\section{ZEW}

Zentrum für Europäische Wirtschaftsforschung GmbH

Centre for European Economic Research

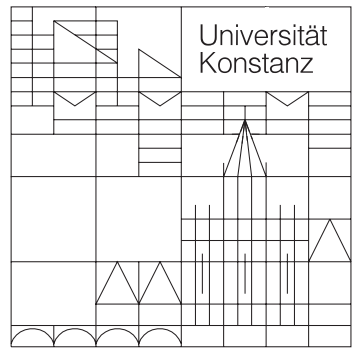

Rechts-, Wirtschafts- und Verwaltungswissenschaftliche Sektion

Fachbereich

Wirtschaftswissenschaften

Diskussionspapiere der DFG-

Forschergruppe (Nr.: 3468269275):

Heterogene Arbeit: Positive und Normative Aspekte der Qualifikationsstruktur der Arbeit

Nikolai Stähler

Employment Protection: Its Effects on Different Skill Groups and on the Incentive to become Skilled

September 2005 
Diskussionspapier der Forschergruppe (Nr.: 3468269275) "Heterogene Arbeit: Positive und Normative Aspekte der Qualifikationsstruktur der Arbeit"

Nr. 05/07, September 2005

\title{
Employment Protection: Its Effects on Different Skill Groups and on the Incentive to become Skilled
}

\section{Nikolai Stähler}

\author{
Johannes-Gutenberg-University Mainz \\ Department of Economics \\ FB03/LS Goerke \\ Jakob-Welder-Weg 4 \\ 55099 Mainz \\ Germany \\ mail: staehl@uni-mainz.de \\ phone: +49-6131-39-25442 \\ fax $+49-6131-39-23827$
}

\section{Zusammenfassung:}

Employment protection affects labour market outcomes and hence the incentive to acquire skills. Using a matching model with two education levels in which workers decide ex-ante on their skill formation, it is shown that employment protection can raise the fraction of skilled workers. This will be the case if workers obtain a sufficiently large fraction of the rent created by skill formation. Furthermore, it will be shown that high-skilled workers face shorter unemployment duration and lower dismissal probabilities. 


\title{
Employment Protection: Its Effects on Different Skill Groups and on the Incentive to become Skilled
}

\author{
Nikolai Stähler* \\ Johannes Gutenberg-University, Mainz
}

September 28, 2005

\begin{abstract}
Employment protection affects labour market outcomes and hence the incentive to acquire skills. Using a matching model with two education levels in which workers decide ex-ante on their skill formation, it is shown that employment protection can raise the fraction of skilled workers. This will be the case if workers obtain a sufficiently large fraction of the rent created by skill formation. Furthermore, it will be shown that high-skilled workers face shorter unemployment duration and lower dismissal probabilities.
\end{abstract}

Keywords: education, employment protection, unemployment, search and matching models

JEL-Code: J 24, J41, J42, J64, J68

*Address correspondence to: Nikolai Stähler, Johannes Gutenberg-University Mainz, Department of Economics (FB03/LS Goerke), Jakob-Welder-Weg 4, 55099 Mainz, Germany. Email: staehl@uni-mainz.de. I would like to thank Florian Baumann, Tim Friehe, Laszlo Goerke, Magnus Hoffmann, Martin Kolmar, Jörg Lingens, and Georg Tillmann for many helpful comments. I especially thank the Deutsche Forschungsgemeinschaft (DFG) for financial support. 


\section{Introduction}

By comparing the data of the population share with tertiary education in each country with country specific indices of the level of employment protection, found in the the recent OECD reports (OECD 2004a and 2004b), we find that countries with high levels of employment protection tend to have a higher level of population share with tertiary education. Particularly, in the European context this observation seems to hold. Countries rated to have relatively high employment protection as Belgium, Finland, Germany, the Netherlands, and Norway have a level of population share with tertiary education exceeding the average level within all OECD countries.

Furthermore, in the OECD employment report (OECD 2004a) it is empirically shown that shorter unemployment duration, better re-employment probabilities and fewer dismissals are an accompaniment of education. But it is claimed in the report itself that "still, little is known about the labour market impact of (...) learning." (OECD 2004a, p. 183).

Next to the fact that the present paper gives a theoretical explanation for shorter unemployment duration, better re-employment chances and fewer dismissals of highly educated workers, it especially focuses on the effect that employment protection has on the ex-ante decision of individuals to obtain education. The existing literature that incorporates employment protection with education solely concentrates on education obtained "on-the-job" (see below a brief description of the literature in more detail). But a huge part of individual skill formation takes place before entering the labour market (for example, the decision whether to get a university degree or not) as the OECD (2004b) shows.

Earlier, the theoretical literature about employment protection analysed the effects of employment protection in models with homogeneous workers. Employment protection decreases dismissals but, at the same time, job creation (see Mortensen and Pissarides 1999, 2001, or Bertola 1990). Heterogeneous workers have only lately been introduced. Those models show that employed high-skilled workers benefit more from the same level of employment protection than employed low-skilled workers (see Guelfi 2004 and Kohns 2000, for example). This will also be confirmed in the present paper.

Effects of employment protection on education have been analysed in models where education is considered to be "on-the-job training". Fella (2005) shows in a model with incomplete contracting that termination restrictions increase the firm's and workers's incentive to invest in training. In his model, termination restrictions do not only include employment protection for workers, but it also investigates penalties in the case the worker quits. The reason for more training is that the restrictions assure a higher probability of obtaining benefits from the investment for both sides, the firm and the worker. Burda (2003) presents a matching model with endogenous education decision. He models education as human capital investment made by firms. He finds through calibration that more employment protection decreases the incentive to education. While employment protection and "on-the-job training" both induce some costs for the firm, stronger employment protection results in lower 
education because the firm tries to compensate for the additional costs of more employment protection by reducing education. In addition, Wasmer (2003) points out that the education decision is not independent of the aggregated state of the labour market. In particular, he shows that through different employment protection rules in the US and Europe, different investments in (specific and general) human capital can partly be explained. The investment in general and human capital is obtained by the worker "on-the-job". If employment protection is low, workers invest less in specific and more in general human capital as their general human capital will be rewarded in the case of a job loss. For sufficiently high employment protection though, their expected returns of specific human capital investments will compensate for the risk of loosing the job (which is now lower with stronger employment protection) and, therefore, induces them to invest more in specific human capital. The argument is in agreement with Bean (1997), who claims that more job security may increase the worker's contribution to the firm. An ex-ante decision on skill formation of workers has been introduced by Sato and Sugiura (2003). They analyse the effects of subsidies on human capital investments and unemployment benefits on skill formation.

In the present paper, firstly, I contribute to the discussion of the effects of employment protection on general human capital investment. I assume that only workers will decide whether they get educated or not. Secondly, I make an additional remark to the discussion that skill formation does not (only) take place "on-the-job" but is done ex-ante by the workers themselves (see OECD 2004b). As employment protection affects "on-the-job" skill formation, it is reasonable to ask the question which effect employment protection has on this decision. Using a matching model in line with Mortensen and Pissarides (1994, 1999, 2001) with two skill groups, I show that, in contrast to Burda (2003), more employment protection increases the incentive to skill formation as long as the worker obtains a sufficiently large fraction of this investment and the education decision is taken by the worker ex ante.

I will proceed as follows. Section 2 describes the basic structure of the model. Section 3 deals with the effect of a change in employment protection on the labour market, education

and unemployment. Section 4 calibrates the model to get some additional insight. In section 5 , the main findings are summarised.

\section{The Model}

The economy is populated by a continuum of individuals which is normalised to one. The economy is continuous in time, and individuals die at rate $\delta$. They are replaced by new born individuals without education at the same rate. At the beginning of their lives and, therefore, before they enter the labour market, each individual has to decide whether to get educated or not. Firms are also measured in a continuum, while their number is determined by the condition of free market entry.

Firms supply jobs, and workers offer their work. The productivity of jobs determines how many jobs are supplied and whether existing jobs are destroyed. These two features 
are captured in the job creation and the job destruction conditions. Unemployment exists due to market frictions and matching problems between employers and employees. There are two separate labour markets, one for the low-skilled and one for the high-skilled. Once educated, high-skilled workers do not move into the low-skilled sector.

The number of high-skilled workers shall be denoted by $A^{s}=\tilde{x}$ and the number of low-skilled workers as $A^{l}=(1-\tilde{x})$, respectively. A Cobb-Douglas matching function, equal in both sectors, $M\left(A^{i} u^{i}, A^{i} v^{i}\right)$, with the typical properties and $i=l, s$ for low- and high-skilled is assumed to capture the market frictions and indicate that job-seeking takes time. ${ }^{1}$ The sector specific unemployment rate is denoted by $u^{i}$, while $v^{i}$ is the corresponding vacancy rate. Unemployment and vacancies exist at the same time. I define the ratio $\theta^{i}=A^{i} v^{i} / A^{i} u^{i}=v^{i} / u^{i}$, which is called market tightness.

Note that it could be reasonable to assume that the matching process in the high- and low-skilled sector differ. The qualitative results of the following analysis are not influenced by that assumption. Therefore, for simplicity, I do without the differentiation and assume the matching function to be equal in both sectors. ${ }^{2}$

The rate at which vacancies are filled is the number of matches, given by the matching function, divided by the number of vacancies in the corresponding sector. In terms of the market tightness, this can be written as $q\left(\theta^{i}\right)$, with $q^{\prime}\left(\theta^{i}\right)<0$. Analogously, the probability of an unemployed finding a job in each sector can be calculated as $\theta^{i} q\left(\theta^{i}\right)$ with $\left(\theta^{i} q\left(\theta^{i}\right)\right)^{\prime}>0$.

The productivity of a given job can be decomposed additively into a global component $p+a^{i}$, with $a^{s}>0$ and $a^{l}=0$, and an idiosyncratic component $\epsilon^{i}$. The idiosyncratic component is a zero-mean shock with $\epsilon^{i} \in\left[\epsilon_{l} ; \epsilon_{u}\right] . \epsilon^{i}$ is distributed according to the cumulative distribution function $G(\epsilon)$, with $g(\epsilon)$ being the corresponding density function and being equal in both sectors. Shocks occur to every job at a Poisson rate $\lambda$. The shock changes the idiosyncratic productivity, drawing a new $\epsilon^{i}$ out of the distribution. If the idiosyncratic productivity falls below the endogenous reservation productivity $\epsilon_{d}^{i}$, the job will be destroyed.

There exist vacancy costs $c$ for each vacancy. Employment protection is captured by dismissal costs $T$ which have to be paid by the firm when firing a worker. $T$ is equal in both sectors since I assume the same level of employment protection to hold for each skill group. $T$ can be interpreted as legal costs for dismissals. ${ }^{3}$

\footnotetext{
${ }^{1}$ Petrongolo and Pissarides (2001), pp. 396 claim that "(t)he stylized fact that emerges from empirical literature is that there is a stable aggregate matching function of a few variables that satisfies the CobbDouglas restrictions with constant returns to scale in vacancies and unemployment". Therefore, the loss of generality assuming a Cobb-Douglas matching function can be justified by the consistence of such a function with empirical facts. Furthermore, it simplifies the analysis later on.

${ }^{2}$ For a Cobb-Douglas matching function, the differentiation can simply be done by assuming functions of the form $M^{s}\left(A^{s} u^{s}, A^{s} v^{s}\right)=\left(A^{s} u^{s}\right)^{\alpha}\left(A^{s} v^{s}\right)^{(1-\alpha)}$ and $M^{l}\left(A^{l} u^{l}, A^{l} v^{l}\right)=\left(A^{l} u^{l}\right)^{\sigma \alpha}\left(A^{l} v^{l}\right)^{(1-\sigma \alpha)}$, where $0<$ $\alpha, \sigma \alpha<1$, for example. I will briefly refer to the resulting quantitative difference in Section 3 .

${ }^{3}$ It can be reasonable to assume that dismissal costs are higher in the high-skilled sector. This can be justified by the assumption that high-skilled workers know more about their legal rights and can afford better lawyers to enforce their rights. Or that workers, when being dismissed, receive a severance payment. For simplification, the basic model setup does without this assumption. The implications will be discussed in
} 
Employers and employees bargain over wages according to a Nash-bargaining process. The wages depend on the job-specific productivity. It is assumed that after each shock the wages are renegotiated. Following Pissarides (2000), only unemployed workers look for a job, while the employed stay on their job until they are dismissed or die.

I assume that individuals are low-skilled at the beginning of their lives, but heterogeneous in their ability to learn. Ability $x$ is uniformly distributed in an interval $x \in[0,1]$, where zero represents the highest ability. The lower an individual's ability to learn, the more units of education $x$ an individual needs to become high-skilled. A unit of education costs $k$. Education takes place infinitely fast at the beginning of the period when the individual is born.

To decide whether to get educated or not, each individual compares the utility value of being low-skilled with the utility value of being high-skilled minus the individual costs of education. I assume that in case of equality, the individual gets educated. As I assume a uniform skill distribution and because the population size is normalized to unity, the resulting threshold value of $x$ is equal to $\tilde{x}$. Each individual with $x>\tilde{x}$ will stay low-skilled (and vice versa). The game structure is according to the following time line.

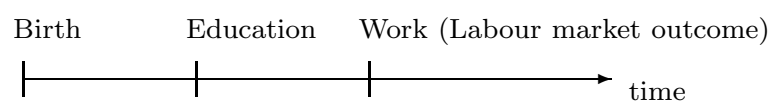

In the first step, after individuals were born, they make their education decision and then, in the second step, enter the labour market. The labour market outcome is then determined as described above. The game is solved by backward induction. Because of the properties of a linear homogeneous matching function, the individual's decision about education does not influence the sector-specific labour market outcome and, therefore, the education decision of others. This is fairly important, and I will get back to this point in more detail later on when turning to the education decision. In the following analysis, I am going to describe the structure of the labour market and then explain the education decision.

\subsection{The Labour Market}

\section{Firms}

In both sectors, each firm has one job to offer which can be either filled or vacant. The number of firms is endogenously determined. The value of the firm $J\left(\epsilon^{i}\right)$ depends on the productivity (overall and idiosyncratic), wages $w\left(\epsilon^{i}\right)$ and option value. Therefore it satisfies the Bellman equation

$$
r J\left(\epsilon^{i}\right)=p+a^{i}+\epsilon^{i}-w\left(\epsilon^{i}\right)+\lambda\left[\int_{\epsilon_{d}^{i}}^{\epsilon_{u}} J(x) d G(x)+G\left(\epsilon_{d}^{i}\right)(-T)-J\left(\epsilon^{i}\right)\right]-\delta J\left(\epsilon^{i}\right) .
$$

Section 3 though. 
$r$ is the interest rate of the economy. In the case of a dismissal, which occurs with probability $\lambda G\left(\epsilon_{d}^{i}\right)$, firms have to pay the amount $T$ to some third party.

Following Pissarides (2000), newly created jobs are endowed with the highest possible idiosyncratic productivity and satisfy the Bellman equation

$$
r J^{0, i}=p+a^{i}+\epsilon_{u}^{i}-w^{0, i}+\lambda\left[\int_{\epsilon_{d}^{i}}^{\epsilon_{u}} J(x) d G(x)+G\left(\epsilon_{d}^{i}\right)(-T)-J^{0, i}\right]-\delta J^{0, i},
$$

with $w^{0, i}$ as initial wage payment.

Analogously to the above one can derive the Bellman equation for a vacancy $V^{i}$ as

$$
r V^{i}=-c+q\left(\theta^{i}\right)\left[J^{0, i}-V^{i}\right] .
$$

The possibility of free market entry for firms implies that vacancies will be created as long as their present value is greater than zero. Accordingly, in equilibrium, $V^{i}=0$ holds. Therefore equation (3) implies

$$
J^{0, i}=\frac{c}{q\left(\theta^{i}\right)}
$$

in equilibrium. Equation (4) says that the discounted value of a newly created job has to equal the search costs $c$ per period multiplied with the average search duration $1 / q\left(\theta^{i}\right)$.

\section{Workers}

Workers can either be employed (with utility $W\left(\epsilon^{i}\right)$ ) or unemployed (with utility $U^{i}$ ). If they are unemployed, they get the option value of finding a job since for simplicity I assume that there are no unemployment benefits. The Bellman equation for the unemployed satisfies

$$
r U^{i}=\theta^{i} q\left(\theta^{i}\right)\left(W^{0, i}-U^{i}\right)-\delta U^{i}
$$

where $W^{0, i}$ is the utility of a newly founded job. The equation for an employed worker reads

$$
r W\left(\epsilon^{i}\right)=w\left(\epsilon^{i}\right)+\lambda\left[\int_{\epsilon_{d}^{i}}^{\epsilon_{u}} W(x) d G(x)+G\left(\epsilon_{d}^{i}\right) U^{i}-W\left(\epsilon^{i}\right)\right]-\delta W\left(\epsilon^{i}\right) .
$$

The employed workers obtain utility of the wage (depending on the sector the corresponding worker is working in) and the option value of a change in the idiosyncratic component. If the idiosyncratic component falls below a certain value $\epsilon_{d}^{i}$, the job is destroyed and the corresponding worker becomes unemployed. If the job has just been created, the corresponding Bellman equation for a newly employed worker is given by

$$
r W^{0, i}=w^{0, i}+\lambda\left[\int_{\epsilon_{d}^{i}}^{\epsilon_{u}} W(x) d G(x)+G\left(\epsilon_{d}^{i}\right) U-W^{0, i}\right]-\delta W^{0, i} .
$$




\section{Job Destruction and Job Creation}

Wage bargaining is modeled as a Nash bargaining between workers and firms, where the bargaining power of workers is $\beta$. The workers' fall back utility is the utility of unemployment, $U$, while the firms' fall back utility are the negative dismissal costs, $-T$. The bargaining can be represented as $w\left(\epsilon^{i}\right)=\arg \max (W(\epsilon)-U)^{\beta}(J(\epsilon)+T)^{1-\beta}$ for the wage of continuing jobs and $w^{0, i}=\operatorname{argmax}\left(W^{0}-U\right)^{\beta} J^{0^{1-\beta}}$ for newly created jobs, because when firms and workers bargain for the first time, firms do not face the threat of having to pay the dismissal costs in the case, bargaining fails (see Mortensen and Pissarides, 2001). The resulting wages are $w\left(\epsilon^{i}\right)=\beta\left[p+a^{i}+\epsilon^{i}+(r+\lambda) T+c \theta^{i}\right]$ and $w^{0, i}=w\left(\epsilon_{u}\right)-\beta(r+\delta+\lambda) T$. Using these wages, we can derive he Job Destruction Condition (further JD), which describes under which circumstances a job is destroyed, as

$$
p+a^{i}+\epsilon_{d}^{i}+\frac{\lambda}{r+\lambda+\delta} \int_{\epsilon_{d}^{i}}^{\epsilon_{u}}\left(z-\epsilon_{d}^{i}\right) d G(z)=\frac{\beta}{1-\beta} c \theta^{i}-(r+\delta) T,
$$

and the Job Creation Condition (further JC), which shows when jobs are created and therefore determines market tightness $\theta^{i}$. It can be derived from using equation (4) and equalises the cost of search with the productive value of a job for the employer. It can be stated as

$$
\frac{(1-\beta)\left(\epsilon_{u}-\epsilon_{d}^{i}\right)}{r+\lambda+\delta}-(1-\beta) T=\frac{c}{q\left(\theta^{i}\right)} \cdot{ }^{4}
$$

By solving equations (8) and (9) simultaneously, one obtains the reservation productivity $\epsilon_{d}^{i}$ and the market tightness $\theta^{i}$ in each sector. Because of the higher sector specific productivity $p+a^{s}$ in the high-skilled sector, the JD for the high-skilled is lower than the one for the low-skilled. Jobs remain productive longer and are, therefore, destroyed later than in the low-skilled sector. This yields $\epsilon_{d}^{s}<\epsilon_{d}^{l}$ and $\theta^{s}>\theta^{l}$. Empirical research tends to confirm this hypothesis, as can be seen in Boeri et al. (2004).

\subsection{Education Decision}

Individuals enter the labour market as unemployed. The utility value of an individual is therefore captured by equation (5). ${ }^{5}$ Thus, for an individual to get educated, the utility of being unemployed for the high-skilled worker minus the individual costs of education has to equal or exceed the utility of being unemployed of the low-skilled worker, $U^{s}-k x \geq U^{l}$. The threshold value of $x$ for an individual to still be willing to get educated can thereby be calculated as $\tilde{x}=\frac{U^{s}-U^{l}}{k}$.

\footnotetext{
${ }^{4}$ For the derivation of equations (8) and (9), I we follow Pissarides (2000). For no employment protection, $T=0$, and $a^{i}=0$ and $\delta=0$, the results are the same. The introduction of $T, a^{i}$, and $\delta$ only changes the conditions according to the above equations.

${ }^{5}$ For this kind of modeling see also Kolm and Larsen (2003), Sato and Sugiura (2003) or Pissarides (2000), chapter 7 .
} 
It can be shown that $W\left(\epsilon_{u}\right)-U=\frac{\beta c}{(1-\beta) q\left(\theta^{i}\right)}$ (see Pissarides $(2000$, p. 41), where $V=0$ in steady state and, therefore, $J^{0}=\frac{c}{q(\theta)}$. Substituting this into (5) yields $U^{i}=\frac{\beta c}{(1-\beta)(r+\delta)} \theta^{i}$ which calculates

$$
\tilde{x}=\frac{\beta c}{(1-\beta)(r+\delta) k}\left(\theta^{s}-\theta^{l}\right)
$$

As equation (10) shows, there is no education without bargaining power $(\beta=0)$. This is because having no bargaining power, workers only receive their reservation wage. This is true across both sectors. The higher the bargaining power, the higher the worker's share of a firm-worker-pair. Therefore, the worker receives higher payoffs on his education investment.

Equation (10), furthermore, states that the decision to get educated mainly depends on the differences of the market tightnesses and, therefore, on the probabilities of finding a job in each sector. The market tightness in each sector is determined in the second stage of the game, which is the labour market outcome. This outcome influences the education decision of individuals before they enter the labour market. But the education decision itself does not influence the labour market outcome in the second stage.

This is due to the matching function which is linear homogeneous of degree one and the free market entry for firms. Independent of how many people in the economy are lowor high-skilled, in steady state, the sector specific market tightness remains the same for given exogenous parameters. ${ }^{6}$ Therefore, the individual's decision in which sector to go does not affect the decision of others and vice versa. The outcome of the second stage of the game (the labour market outcome) enters into the first stage (education decision) as a given parameter, while the first stage does not influence the second stage of the game. If more people decide to get educated, more vacancies in the high-skilled sector are supplied and vice versa. Therefore, the original sequential structure can be dropped. Hence there exists no reaction function of individuals.

\subsection{Unemployment}

Unemployment is determined by inflows $\left(\lambda G\left(\epsilon_{d}^{i}\right)\left(1-u^{i}\right) A^{i}+\delta A^{i}\right)$ into and outflows $\left(\theta^{i} q\left(\theta^{i}\right) u^{i}+\right.$ $u^{i} A^{i} \delta$ ) out of unemployment in each sector. In steady state the changes of unemployment will be zero. Thus the steady state unemployment rate for each sector can be derived as

$$
u^{i}=\frac{\lambda G\left(\epsilon_{d}^{i}\right)+\delta}{\lambda G\left(\epsilon_{d}^{i}\right)+\theta^{i} q\left(\theta^{i}\right)+\delta} .
$$

\footnotetext{
${ }^{6}$ In the end, the probability only depends on unemployment and vacancy rates, not on the number of people in each sector. Increasing the number of, for example, unemployed people in one sector leads to a decrease in market tightness. This increases the probability of a vacancy being filled, which increases the value of the vacancy (see equation (3)). Because of free market entry, a corresponding number of vacancies will be offered, lowering the market tightness to its original equilibrium value again. This also works when the number of the unemployed is decreased or vacancies are decreased and increased.
} 
To calculate the total number of unemployed in the whole economy, I multiply the unemployment rate (11) with the corresponding number of workers in this sector $A^{i}$ and add the resulting numbers of unemployed workers of each sector $\left(u^{*}=u^{l}(1-\tilde{x})+u^{s} \tilde{x}\right)$. Since population is normalised to one, $u^{*}$ at the same time gives the total number of the unemployed in the economy as well as the overall unemployment rate in the economy. Doing so after some rearranging yields

$$
u^{*}=\frac{(1-\tilde{x}) \theta^{s} q\left(\theta^{s}\right)\left(G\left(\epsilon_{d}^{l}\right)+\delta\right)+\left(\tilde{x} \theta^{l} q\left(\theta^{l}\right)+G\left(\epsilon_{d}^{l}\right)+\delta\right)\left(G\left(\epsilon_{d}^{s}\right)+\delta\right)}{\left[\lambda G\left(\epsilon_{d}^{l}\right)+\theta^{l} q\left(\theta^{l}\right)+\delta\right]\left[\lambda G\left(\epsilon_{d}^{s}\right)+\theta^{s} q\left(\theta^{s}\right)+\delta\right]} .
$$

\section{Analysis}

It is straightforward to show that employed high-skilled workers benefit more from employment protection than low-skilled workers. For this to be the case, $\frac{d \epsilon_{d}^{s}}{d T}<\frac{d \epsilon_{d}^{l}}{d T}$ has to hold. It has already been shown by Guelfi (2004) and Kohns (2000) in a slightly different model framework that this condition holds. It can be easily shown that it also holds in this model framework (for a proof, see Appendix A). As it has already been demonstrated above that high-skilled workers face a higher re-employment probability and shorter unemployment duration than low-skilled workers (resulting from $\theta^{s}>\theta^{l}$ ), the question of how an increase in employment protection changes the ex-ante decision of individuals on skill formation arises.

To show which effect a change in employment protection has on education, recall equation (10). Differentiating (10) with respect to firing costs $T$ yields

$$
\frac{d \tilde{x}}{d T}=\frac{\beta c}{(1-\beta)(r+\lambda) k}\left(\frac{d \theta^{s}}{d T}-\frac{d \theta^{l}}{d T}\right) .
$$

By totally differentiating the JD and JC, equations (8) and (9), we can derive

$$
\frac{d \theta^{i}}{d T}=\frac{(1-\beta) \lambda G\left(\epsilon_{d}^{i}\right)}{\left(r+\delta+\lambda G\left(\epsilon_{d}^{i}\right)\right) \frac{c}{q\left(\theta^{i}\right)^{2}} q^{\prime}\left(\theta^{i}\right)-\beta c}<0 .
$$

The change in market tightness due to a change in employment protection in both sectors differs in the original level of reservation productivity and market tightness. Increasing employment protection yields an increase in education if equation (13) has a positive sign. This is the case only if $\frac{d \theta^{l}}{d T}<\frac{d \theta^{s}}{d T}$ holds, because the decrease in market tightness of the low-skilled must be greater than the one of the high-skilled (and vice versa). Equation (14) in combination with equation (13) yields

$$
\left(\frac{G\left(\epsilon_{d}^{l}\right)}{G\left(\epsilon_{d}^{s}\right)} \frac{\left(r+\delta+\lambda G\left(\epsilon_{d}^{s}\right)\right)}{\left(r+\delta+\lambda G\left(\epsilon_{d}^{l}\right)\right)}+\beta \frac{G\left(\epsilon_{d}^{l}\right)-G\left(\epsilon_{d}^{s}\right)}{G\left(\epsilon_{d}^{s}\right)\left(r+\delta+\lambda G\left(\epsilon_{d}^{l}\right)\right)} \frac{\theta^{s} q\left(\theta^{s}\right)}{\bar{\eta}}\right)>\frac{\theta^{s} q\left(\theta^{s}\right)}{\theta^{l} q\left(\theta^{l}\right)},{ }^{7}
$$

\footnotetext{
${ }^{7}$ Note that equation (15) can easily be derived by substituting equation (14) into $\frac{d \theta^{l}}{d T}<\frac{d \theta^{s}}{d T}$. After
} 
which after the exemption of $\beta$ yields

$$
\beta>\left(\frac{\theta^{s} q\left(\theta^{s}\right)}{\theta^{l} q\left(\theta^{l}\right)}-\frac{G\left(\epsilon_{d}^{l}\right)}{G\left(\epsilon_{d}^{s}\right)} \frac{\left(r+\delta+\lambda G\left(\epsilon_{d}^{s}\right)\right)}{\left(r+\delta+\lambda G\left(\epsilon_{d}^{l}\right)\right)}\right) \frac{G\left(\epsilon_{d}^{s}\right)\left(r+\delta+\lambda G\left(\epsilon_{d}^{l}\right)\right) \bar{\eta}}{\left(G\left(\epsilon_{d}^{l}\right)-G\left(\epsilon_{d}^{s}\right)\right) \theta^{s} q\left(\theta^{s}\right)}=\widehat{\beta}, 8
$$

where $0<\bar{\eta}=-\frac{q^{\prime}\left(\theta^{l}\right)}{q\left(\theta^{l}\right)} \theta^{l}=-\frac{q^{\prime}\left(\theta^{s}\right)}{q\left(\theta^{s}\right)} \theta^{s}<1$ for a Cobb-Douglas matching function. Equation (16) states that as long as the bargaining power of workers exceeds some threshold value $(\beta>\widehat{\beta})$, education increases when increasing employment protection. The threshold value $\widehat{\beta}$ consists of the relative duration of unemployment between low- and high-skilled (first term in brackets) minus the relative dismissal probability between low- and high-skilled (second term in brackets), weighted by the relation between dismissal and re-employment probability in the high-skilled sector $\left(\frac{G\left(\epsilon_{d}^{s}\right)\left(r+\delta+\lambda G\left(\epsilon_{d}^{l}\right)\right.}{\theta^{s} q\left(\theta^{s}\right)}\right)$ as well as the relation of the differences of changes in market tightness and dismissal probabilities $\left(\frac{\bar{\eta}}{G\left(\epsilon_{d}^{l}\right)-G\left(\epsilon_{d}^{s}\right)}\right)$.

The intuition is clear. The probability of finding a job in each sector decreases with an increase in employment protection. Obviously, it depends on the relative decrease of those probabilities. If the probability in the low-skilled sector decreases by more, it gets relatively easier in the high-skilled sector to find a job. Therefore, more people get educated.

The higher the bargaining power, the higher the worker's share of a firm-worker-match. If the bargaining power of workers is high enough $(\beta>\widehat{\beta})$, an increase in employment protection lowers the value of newly created jobs in the low-skilled sector by relatively more. So supplying relatively fewer vacancies in the low-skilled sector is attractive for the firm since the firm only receives $(1-\beta)$ from the surplus of a job. The opposite holds for $\beta<\widehat{\beta}$. Therefore, if more employment protection increases or decreases the level of education crucially depends on the bargaining power of workers.

Different dismissal costs in both skill sectors do not change the qualitative results of the above analysis. The only difference is that if dismissal costs are higher in the low(high-) skilled sector, the original market tightness of the corresponding sector will be lower, changing the original education decision according to equation (10). Note that there is one exception. Assume that employment protection in the high-skilled sector is stronger. Then, the higher expected dismissal costs can overcompensate the productivity advantage to the

multiplying by $c$, finding the least common denominator of both sides, adding $\beta G\left(\epsilon_{d}^{s}\right)$, and dividing by $G\left(\epsilon_{d}^{s}\right)\left(\left(r+\delta+\lambda G\left(\epsilon_{d}^{l}\right)\right)\right.$ and $\frac{q^{\prime}\left(\theta^{s}\right)}{q\left(\theta^{s}\right)^{2}}$, the resulting equation is enhanced by $\frac{\frac{\theta^{l}}{\theta^{l}}}{\theta^{s}}=1$ and $\theta^{i} q\left(\theta^{i}\right)$ is switched from the rhs to the lhs. Bearing in mind that $\eta^{i}=-\frac{q^{\prime}\left(\theta^{i}\right)}{\theta^{i} q\left(\theta^{i}\right)}$ and $\eta^{l}=\eta^{s}=\bar{\eta}$ for a Cobb-Douglas matching function, after multiplication with $\theta^{s} / \theta^{s}=1$ and substitution of $\eta^{s}$, equation (15) is achieved.

${ }^{8}$ If it was assumed that the matching function differs in both sectors according to footnote (2), the first term in brackets of $\widehat{\beta}, \frac{\theta^{s} q\left(\theta^{s}\right)}{\theta^{l} q\left(\theta^{l}\right)}$, would have to be multiplied by $\sigma$. Furthermore, $\bar{\eta}$ would have to be substituted by $\eta^{s}=\alpha$. For $0<\sigma<1$, implying a better matching process in the high-skilled sector, the threshold value $\widehat{\beta}$ for workers to get more education decreases. Because of better matching in the high-skilled sector, the market tightness relatively decreases even more in the low-skilled sector when employment protection is increased. This implies that workers will need to be less compensated for their investment in education. The opposite holds for a better matching process in the low-skilled sector, $\sigma>1$. 
low-skilled sector, yielding a lower market tightness in the high-skilled sector. That means that there will be no education from the start as it does not pay from the workers point of view. ${ }^{9}$ In this case, only a decrease in employment protection can result in more education.

It is also reasonable to assume that workers are entitled to receive a severance payment when being dismissed. Again, in principle, the argumentation does not change and education will still increase when increasing the severance payment, as long as workers obtain a sufficiently large fraction of the rent created by their education investment. The difference in presence of severance payments is that the wage claim of workers increases, because their fall back utility increases by the possibility to receive the severance payment in the case of a dismissal. An increase of the level of severance payment also decreases market tightness in both sectors and the effect of education depends on the relation of the decrease of market tightnesses according to equation (13). It has to be noted though that the decrease of market tightness in presence of severance payments in each sector differs compared to the situation with pure firing costs as presented in the present paper. From a theoretical point of view, it is not possible to say if the decrease of market tightness in presence of severance payments exceeds or falls short of the decreases presented in the present paper due to the additional wage effect. Nevertheless, for education to increase when the level of severance payments is increased, there will result a computable threshold value for $\beta$ which resembles the one of equation (16). ${ }^{10}$

It is straightforward to show that the fact that more workers get educated reduces unemployment. To prove that, I derive equation (12) with respect to $k$.

$$
\frac{\partial u^{*}}{\partial k}=\frac{\left(G\left(\epsilon_{d}^{s}\right)+\delta\right) \theta^{l} q\left(\theta^{l}\right)-\left(G\left(\epsilon_{d}^{l}\right)+\delta\right) \theta^{s} q\left(\theta^{s}\right)}{\left(\lambda G\left(\epsilon_{d}^{l}\right)+\theta^{l} q\left(\theta^{l}\right)+\delta\right)\left(\lambda G\left(\epsilon_{d}^{s}\right)+\theta^{s} q\left(\theta^{s}\right)+\delta\right)} \frac{\partial \tilde{x}}{\partial k},
$$

where $\frac{\partial \tilde{x}}{\partial k}<0$. Since it has already been demonstrated that $\epsilon_{d}^{s}<\epsilon_{d}^{l}$ and $\theta^{s}>\theta^{l}$, it is obvious that the first term on the rhs, $\frac{\partial u^{*}}{\partial \tilde{x}}$, has a negative sign. Therefore equation (17) has a positive sign. Now decreasing education costs $k$ increases the education level $\tilde{x}$ and therefore reduces unemployment.

The economic intuition is as follows. As can be seen in equation (11) in combination with (17) the unemployment rate in the high-skilled sector is lower than in the low-skilled sector. If more people move from the low-skilled sector to the high-skilled sector, less people are unemployed and therefore the overall unemployment rate falls.

Still, the effect of employment protection on overall unemployment is ambiguous since the effects on the unemployment rates in each sector are unclear like in many existing publications (see Pissarides 2000). Employment protection leads to fewer dismissals, but at

\footnotetext{
${ }^{9}$ Note that according to equation (10) that would result in a negative $\widetilde{x}$. As this is economically impossible, this option is excluded. All mathematical solutions for $\widetilde{x}<0$ are set to $\widetilde{x}=0$ as there cannot be a negative education level.

${ }^{10} \mathrm{~A}$ proof for the argumentation about different sector specific levels of employment protection and severance payments is presented to the referee and will be send upon request.
} 
the same time to fewer vacancies, which implies fewer inflows into and fewer outflows out of unemployment. It is not clear, which of the two effects dominates.

In the present model, an additional effect is introduced. Education, as has been shown above, can be positively influenced by employment protection. Education in itself negatively influences the unemployment rate. Therefore, the effect of employment protection on unemployment differs through the educational channel to standard results. In case unemployment increases (decreases), this effect is weakened (boosted) by the negative effect education has on unemployment when employment protection is increased and $\beta>\widehat{\beta}$.

\section{Calibration}

To better assess the magnitude of the effects of employment protection on different skill groups and on the incentive to become skilled, I perform a simple calibration of the model. Following Mortensen and Pissarides (1999), I assume that the distribution of idiosyncratic productivity $\epsilon$ is uniform, here over $[-1,1]$ and, therefore, $G(\epsilon)=\frac{1}{2}[1+\epsilon]$ being the cumulative distribution function. Furthermore, $q\left(\theta^{i}\right)=\left(\theta^{i}\right)^{-\alpha}$, with $0<\alpha<1$. The values of the parameters are presented in Table 1 and intend to reflect the European case (Scenario 1) and the U.S. case (Scenario 2). Scenario 3 is added to show that it also holds for other parametric specifications.

\begin{tabular}{|c|c|c|c|}
\hline Parameter & Scenario 1 (Sc.1) & Scenario 2 (Sc.2) & Scenario 3 (Sc.3) \\
\hline$p$ & 1.75 & 1.75 & 1.75 \\
$a^{s}$ & 0.5 & 0.5 & 0.3 \\
$r$ & 0.05 & 0.05 & 0.03 \\
$\lambda$ & 0.7 & 0.3 & 0.3 \\
$c$ & 0.3 & 0.3 & 0.3 \\
$\beta$ & 0.5 & 0.5 & 0.5 \\
$\delta$ & 0.05 & 0.05 & 0.1 \\
$k$ & 7.5 & 7.5 & 3.5 \\
$\eta=\alpha$ & 0.5 & 0.5 & 0.5 \\
\hline
\end{tabular}

Table 1: Parameter Values

The values are chosen to obtain an unemployment rate of about $8.8 \%$ for Europe (Scenario 1) and $6.5 \%$ for the US (Scenario 2) accorrding to the actual employment report of the OECD (2004a) at an employment protection level $T=0$. The resulting unemployment rate for Scenario 3 is $5.7 \%$. Furthermore, the bargaining power is chosen to be $\beta=\alpha=\eta$, according to the condition of Hosios (1990). ${ }^{11}$ Broersma and van Ours (1999) find empirically that it is

\footnotetext{
${ }^{11}$ The qualitative results of the above calibrations do not change if this is not the case. But following a standard assumption when calibrating matching models, this is assumed to hold here as well.
} 
reasonable to assume $\eta=0.5$. In all three scenarios, $\beta>\widehat{\beta}$. The above theoretical analysis predicts an increase in the level of education if employment protection is increased.

It is apparent from Figure 1 that the level of education $\tilde{x}$ increases with employment protection $T$ in all three scenarios as all three graphs have an ascending slope. ${ }^{12}$ That is because workers obtain a sufficiently large fraction of the investment in skill formation, since with these parameter constellations, $\beta>\widehat{\beta}$ (as can be seen in Figure 2) for all $T$ that yield an economically reasonable solution for the unemployment rate. ${ }^{13}$

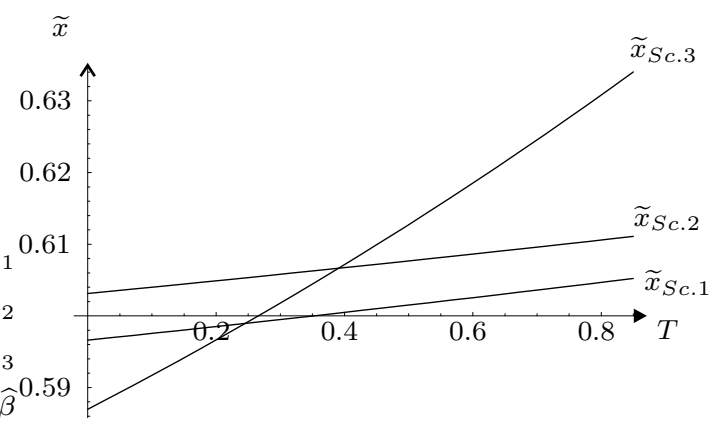

Figure 1: Education Level

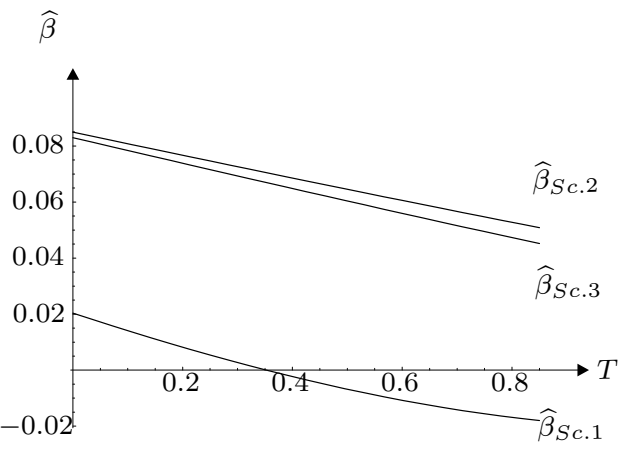

Figure 2: Threshold $\widehat{\beta}$

Furthermore, using these parameter constellations it can be shown that the levels of unemployment in both sectors and therefore in the entire economy fall when employment protection is increased. The simulation makes possible the conclusion that more employment protection can increase the level of education and decrease unemployment as long as the bargaining power of workers is big enough.

\section{Conclusions}

The main result of this paper is that more employment protection increases the level of education acquired by workers ex ante as long as workers obtain a sufficiently large fraction of the rent resulting from skill formation. That is due to the fact that increasing employment protection relatively increases the (re-)employment chances of high-skilled workers through market tightness. In addition to the better re-employment chances of high-skilled workers, it can be shown that high-skilled workers get dismissed later than low-skilled workers and benefit more from an increase in employment protection. Furthermore, a high level of education unambiguously decreases unemployment.

\footnotetext{
${ }^{12}$ The calibration allows for the speculation that a lower level of education costs, $k$, amplifies the increase of education as the slope of scenario 3 is much steeper than the one of scenarios 1 and 2 .

${ }^{13}$ Economically reasonable solutions are those solutions where the unemployment rates do not fall below zero, which can be a mathematical solution in case $T>0.85$.
} 
This paper complements Burda (2003) and Wasmer (2003). In their works, they suggest that education is achieved "on-the-job". While Burda (2003) finds that more employment protection decreases education, Wasmer (2003) finds the opposite. That is due to the fact in the model presented by Burda (2003), the firm bears the costs of education, while in the model by Wasmer (2003), the worker faces those costs. Next to the fact that it is important who pays for education, we introduce a novel argument to the discussion. It is not only important who pays for education, but also when the education decision takes place. As a huge part of workers' skill formation is done before they enter the labour market (OECD 2004b), this is an interesting topic to think about. Despite the fact that it might seem odd to use employment protection as an instrument to increase education, we have seen that education can be increased by more employment protection under the above mentioned conditions. Especially for developed countries, this argument might be interesting, as it is often claimed that in times of globalisation there can only be kept comparative advantages through higher innovation and well educated workers.

Nevertheless, the results should not be misinterpreted as a pleading for more employment protection. As we have also seen, the ambiguity of the effect an increase of employment protection has on overall unemployment cannot be resolved. Only the pressure of a possible increase in unemployment when employment protection is increased decreases. Further research into different types of employment protection needs to be done.

\section{Mathematical Appendix}

\section{A Who benefits more from employment protection?}

Employed high-skilled workers obtain more benefits from employment protection if reservation productivity of high-skilled workers falls by more than the one for low-skilled workers when employment protection is increased $\left(\frac{d \epsilon_{d}^{s}}{d T}<\frac{d \epsilon_{d}^{l}}{d T}\right)$. Totally differentiating the JD and JC, equations (8) and (9), yields

$$
\frac{d \epsilon_{d}^{i}}{d T}=-\frac{(r+\delta+\lambda)(r+\delta) c q^{\prime}\left(\theta^{i}\right)-q\left(\theta^{i}\right)^{2} \beta c}{\left(r+\delta+\lambda G\left(\epsilon_{d}^{i}\right)\right) c q^{\prime}\left(\theta^{i}\right)-q\left(\theta^{i}\right)^{2} \beta c} .
$$

The above condition $\left(\frac{d \epsilon_{d}^{s}}{d T}<\frac{d \epsilon_{d}^{l}}{d T}\right)$ yields

$$
\begin{aligned}
\lambda\left(G\left(\epsilon_{d}^{s}\right)-G\left(\epsilon_{d}^{l}\right)\right)< & \frac{\beta}{\bar{\eta}}\left(\frac{(r+\delta+\lambda)(r+\delta)+\left(r+\delta+\lambda G\left(\epsilon_{d}^{l}\right)\right)}{(r+\delta+\lambda)(r+\delta)} \theta^{s} q\left(\theta^{s}\right)\right. \\
& \left.-\frac{(r+\delta+\lambda)(r+\delta)+\left(r+\delta+\lambda G\left(\epsilon_{d}^{s}\right)\right)}{(r+\delta+\lambda)(r+\delta)} \theta^{l} q\left(\theta^{l}\right)\right)
\end{aligned}
$$

where $0<\bar{\eta}=-\frac{q^{\prime}\left(\theta^{l}\right)}{q\left(\theta^{l}\right)} \theta^{l}=-\frac{q^{\prime}\left(\theta^{s}\right)}{q\left(\theta^{s}\right)} \theta^{s}<1$ for a Cobb-Douglas matching function. 
Since $\epsilon_{d}^{s}<\epsilon_{d}^{l}$ and $\theta^{s}>\theta^{l}$, as shown above, the lhs in equation (19) is smaller zero, while the rhs is larger. That means, employed high-skilled workers benefit more from the same level of employment protection than employed low-skilled workers.

This is due to the fact that when changing employment protection, the original levels of reservation productivity and market tightness differ in both sectors due to the productivity difference. The higher the productivity difference $a^{s}$, the more beneficial is the effect of increasing employment protection for the employed high-skilled compared to the employed low-skilled workers.

\section{References}

Bean, C. R. (1997), Comment to: Exploring the Political Economy of Labour Market Institutions by Gilles Saint-Paul. Economic Policy, Vol. 23, pp. 265 - 292.

Bertola, G. (1990), Job Security, Employment and Wages. European Economic Review, Vol. 34(4), pp. 851-886.

Boeri, T., J. I. Conde-Ruiz, and V. Galasso (2004), Cross-skill Redistribution and the Tradeoff between Unemployment Benefits and Employment Protection. IZA Discussion Paper, No. 1371.

Broersma, L. and J. C. van Ours (1999), Job Searchers, Job Matches and the Elasticity of Matching. Labour Economics, Vol. 6(1), pp. 77-93.

Burda, M. (2003), Humankapital und Arbeitsmarktinstitutionen bei gleichgewichtiger Arbeitslosigkeit. Bildung - Wirtschaftswissenschaftliches Seminar Ottobeuren, W. Franz, H. J. Ramser and M. Stadler (eds.), Band 33, Mohr Siebeck, Tübingen.

Fella, G. (2005), Termination Restrictions and Investment in General Training. European Economic Review, Vol 49(6), pp. 1479-1499.

Guelfi, A. (2004), Employment Protection and the Incidence of Unemployment: A Theoretical Framework. Labour, Vol. 18(1), pp. 29-52.

Hosios, A. J. (1990), On the Efficiency of Matching and Related Models of Search Unemployment. Review of Economic Studies, Vol. 57(2), pp. 279-298.

Kohns, S. (2000), Different Skill Levels and Firing Costs in a Matching Model with Uncertainty - An Extension of Mortensen and Pissarides (1994). IZA Discussion Paper, No. 104.

Kolm, A. and B. Larsen (2003), Social Norm, the Informal Sector, and Unemployment. FinanzArchiv, Vol. 59(3), 407-424. 
Mortensen, D. T. and C. Pissarides (1994), Job Creation and Job Destruction in the Theory of Unemployment. Review of Economic Studies, Vol. 61(3), 397-415.

Mortensen, D.T. and C. Pissarides (1999), New Developments in Models of Search in the Labor Market. Handbook of Labor Economics, O. Ashenfelter and D. Card (eds.), Vol. 3B, Elsevier, Amsterdam, pp. 2567-2627.

Mortensen, D. T. and C. Pissarides (2001), Taxes, Subsidies, and Equilibrium Labour Market Outcomes. CEPR Discussion Paper, No. 2989.

OECD (2004a), Employment Outlook. Paris.

OECD (2004b), Education at a Glance 2004. Paris.

Petrongolo, B. and C. Pissarides (2001), Looking into the Black Box: A Survey of the Matching Function. Journal of Economic Literature, Vol. 39(2), pp. 390-431.

Pissarides, C. (1998), The Impact of Employment Tax Cuts on Unemployment and Wages; The Role of Unemployment Benefits and Tax Structure. European Economic Review, Vol. 42(1), pp. 155-183.

Pissarides, C. (2000), Equilibrium Unemployment Theory. Cambridge USA: MIT Press.

Pissarides, C. (2001), Employment Protection. Labour Economics, Vol. 8(2), pp. 131-159.

Sato, Y. and H. Sugiura (2003), On Labor Policies Affecting Investment in General Human Capital. Labour, Vol. 17(4), pp. 599-622.

Wasmer, E. (2003), Interpreting Europe and US Labor Markets Differences: The Specificity of Human Capital Investment. CEPR Discussion Paper, No. 3780. 